\title{
Lusioersily
}

\section{Mixed Reality Cubicles and Cave Automatic Virtual Environment}

Onime, C., Uhomoibhi, J., \& Wang, H. (2016). Mixed Reality Cubicles and Cave Automatic Virtual Environment. In Unknown Host Publication (pp. 1-8). IEEE Computer Society. https://doi.org/10.1109/IUCC-CSS.2016.8

Link to publication record in Ulster University Research Portal

\author{
Published in: \\ Unknown Host Publication
}

Publication Status:

Published (in print/issue): 14/12/2016

DOI:

10.1109/IUCC-CSS.2016.8

\section{Document Version}

Publisher's PDF, also known as Version of record

\section{General rights}

Copyright for the publications made accessible via Ulster University's Research Portal is retained by the author(s) and / or other copyright owners and it is a condition of accessing these publications that users recognise and abide by the legal requirements associated with these rights.

\section{Take down policy}

The Research Portal is Ulster University's institutional repository that provides access to Ulster's research outputs. Every effort has been made to ensure that content in the Research Portal does not infringe any person's rights, or applicable UK laws. If you discover content in the Research Portal that you believe breaches copyright or violates any law, please contact pure-support@ulster.ac.uk. 


\section{Mixed Reality Cubicles and Cave Automatic Virtual Environment}

\author{
C. Onime \\ International Centre for Theoretical Physics \\ Trieste, 34151, Italy \\ Email: onime@ictp.it
}

\author{
J. Uhomoibhi \\ University of Ulster \\ Belfast, Northern Ireland \\ Email: j.uhomoibhi@ulster.ac.uk
}

\author{
H. Wang \\ University of Ulster \\ Belfast, Northern Ireland \\ Email: h.wang@ulster.ac.uk
}

\begin{abstract}
In Cave Automatic Virtual Environments (CAVEs), a computer generated environment is projected all around a user to fully immerse or eliminate all reference to the real world. Typically, Virtual Reality (VR) CAVEs also track and respond to the user's physical orientation, movements and gestures. Mixed reality environments instead focus on combining real world objects with computer generated ones. In this paper, we focus on the application of Augmented Reality (AR) as a mixed reality technology via (or to) mobile devices such as head-mounted devices, smart-phones and tablets. We present the development of mixed reality applications for mobile (smart-phone and tablet) devices leading up to the implementation of an mixed reality (AR) cubicle for immersive Three Dimensional (3D) visualizations. We also present the results of a study on the familiarity with both VR and AR technologies among students from two institutions of tertiary education. The paper concludes with a discussion of planned deployment and upgrade of mixed reality cubicles using mobile VR equipment.
\end{abstract}

Keywords-mixed-reality; CAVE; mobile-computing;

\section{INTRODUCTION}

Virtual Reality (VR) and Augmented Reality (AR) are two technologies that are changing the future directions of ubiquitous computing. Humans typically perceive and relate with their surrounding environment using the five physiological senses of sight, smell, touch, sound and taste, although sight, sound and touch are more readily used. Reality may be considered as a state of having existence, substance or objects that may be actually experienced and/or seen [1], while virtuality may be considered as having a virtual view of objects, that is opposite of an idealistic, realistic or notional view. This opposing relationship between reality on the one hand and virtuality on the other hand is illustrated in Figure 1, where the mixed-reality environment is in-between the real and virtual ends of the continuum.

Traveling along the continuum from left to right represents diminishing reality (or reduction in real objects) and increasing virtuality (increase in virtual objects) resulting in the complete absence of real objects at the virtual end. In other words, in VR, the environment is completely made up of virtual objects. The continuum identifies two different kinds of mixed reality, which are Augmented Reality (AR) and Augmented Virtuality (AV). Unlike VR, in Augmented Reality (AR), the goal is not to exclude the real objects but to blend additional or computer generated information into the real world. While in AV, the goal is to blend real objects (data or information from real world) into a computer generated environment. In AR form of mixed-reality, special real objects known as markers are typically used as place holders that indicate the relative entry-points/positions and/or orientation of virtual objects within a real environment. Typically, the marker is a graphical image that should be recorgnised at run-time from different distances, resolutions and angles. From Figure 1, it is not difficult to imagine a hypothetical central point of the continuum (between AR and AV) that represent a situation of balance, or equal number of real and virtual objects, [2] describes this as the point where it is no longer possible to distinguish the real world from the virtual world. In general, the mixed reality environment described by the continuum may be simplified as the integration of real and virtual objects as shown in Equation 1.

$$
E_{M R}=\int(R+V)
$$

Where $E_{M R}$ represents the mixed reality environment, $R$ the set of real objects and $V$ the set of virtual objects. It follows that

$$
E_{M R}= \begin{cases}E_{R}, & \text { if } V=0 \\ E_{A R}, & \text { if } R>V \\ E_{A V}, & \text { if } R<V \\ E_{V R}, & \text { if } R=0\end{cases}
$$

Where $E_{R}, E_{A R}, E_{A V}$ and $E_{V R}$ represent the Real, AR, $\mathrm{AV}$ and VR environments respectively.

\section{A. Virtual Reality (VR)}

Apart from the presence of real versus absence of virtual objects, [3] describes VR as a Three Dimensional (3D) computer-generated simulation oriented environment that allows users to interact at various levels in a more natural manner using interface devices and peripherals such as 3D eye-wear and trackers. An alternative and broader definition portrays VR as a technology that attempts to provide 3D interactions with a computer in new ways with emphasis on the heightened use of the human senses of sight, sound 


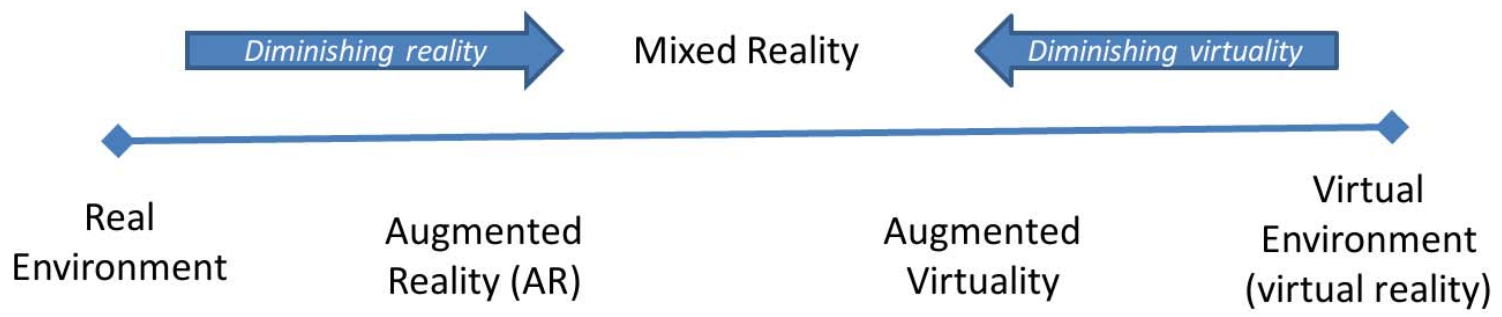

Figure 1. Reality-Virtuality Continuum. Adapted from [2]

and touch. For example, spatialized sound may be used to provide direction such as sound growing louder as the user approaches [4]. Within VR environments, haptic devices allow users to touch surfaces, grasp and move virtual objects, possibly obtaining feedback/reactions them [5], [6].

In VR, the user undergoes an immersion or the psychological experience of loosing himself in the computer (digitally) generated environment (virtual space or world) that may be sometimes modeled after or based on an existing (real) environment. In such virtual world(s), everything is possible as typical laws of physics such as gravity and time may be modified or eliminated completely and the users can (within its confines) overcome limitations that were previously imposed by the physical world [7].

[8] classified VR into non, semi and fully immersive systems, according to the degree of immersion experienced by the users. In non-immersive VR systems, users do not have a stereo view and/or experience of the virtual environment. Semi-immersive VR systems provide a bigger view of the computer generated environment mainly through use of a large screen device or special eye-wear (or goggles), commonly combined with special input devices such as wands, gloves or controllers. Fully-immersive VR systems provide a total (3D) view of the computer generated environment obtained using multiple large screen devices or special eyewear along with special input devices such as touch-screens, wands, gloves and controllers.

Figure 2 shows two different examples of VR environments, the first represents an indoor environment with various bits of furniture including chairs, a sofa and a painting, while the second is an outdoor view of a well developed water-front.

In many VR systems as discussed in Section II, full immersion occurs when all references to the real world environment are completely removed by housing the user in specially designed Cave Automatic Virtual Environment (CAVE) environments(s) or using special head-mounted displays (HMD) (helmet devices with mounted displays) for mobility. This paper discusses obtaining similar heightened (fully) immersive experience using mixed-reality technology and Section III presents the development, limitations of a

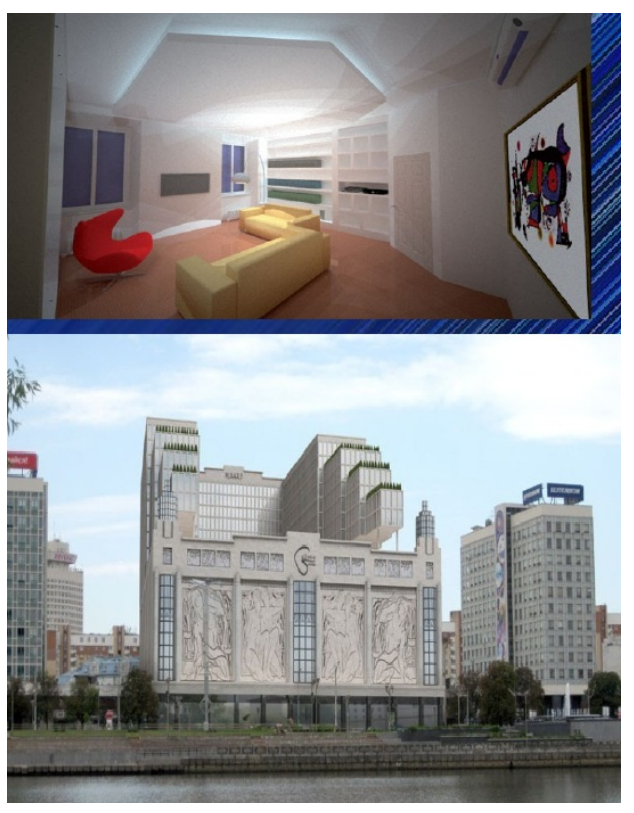

Figure 2. Examples of VR environments. [9]

fully immersive mixed-reality cubicle and results of a joint study on familiarity with both VR and AR technologies at two different academic institutions, while Section IV concludes the paper.

\section{RELATED WORKS}

There are already, many diverse applications of VR technology in various sectors; for example, [8] reported that, it has been used as a platform to study the behaviour (of humans) in a controlled environment or the differences in behaviour between the controlled environment and the real physical world. It has also been used as a platform for teaching specialized procedures to pilots [10] and doctors [11] without the associated risks involved in a real environment. In the education sector, there are on-line resources that use non-immersive VR related techniques to provide several chemistry laboratory experiments/exercises, as well as, simulation of a chemistry laboratory through use of rich media powered by JavaScript [12]. 
In civil engineering, building technology and architecture, VR based prototyping is also commonly used to provide a $3 \mathrm{D}$ view (or $3 \mathrm{D}$ printed model) of objects with varying levels of abstraction [13].

Virtual reality is used in the gaming industry (massive online role playing games), where it is used to provide the interactive display of 3D objects. Both Two Dimensional (2D) and 3D visualization/animation (sometimes from VR) play increasingly important roles in scientific research especially those involving modeling and simulation. VR is also used on-line, however, the full potential (or immersive nature) of $\mathrm{VR}$ is not possible when using the traditional User Interface (UI) of end-user computers.

\section{A. Cave Automatic Virtual Environment (CAVE)}

In most implementations of CAVEs, the walls (including floor and ceiling) are replaced by large (wall-sized) displays or projection screens arranged such that the computer generated (virtual) environment is projected all around the user. Within CAVEs, VR systems also have to track and respond to, the user's physical orientation, movements and gestures. Sometimes, this may involve the use of special hand-gloves or body suits suitable for tracking movements in very fine detail. At other times, this may involve the use of suitable sensors. A good example is the CAVE roomsized VR system of [14]. Another example is the Wall-sized Interaction with Large Datasets (WILD) room [15]. Where a wall-sized display is combined with a multitouch table and various mobile devices specifically to help scientists collaborate on the analysis of large and complex datasets [16]. In WILD, the CAVE room could be used by a group of microbiologist (co-located inside the CAVE) to study how one molecule docks with another and interactively and seamlessly switch between several 3D representations, different molecular models, online databases, websites and research articles along with the ability to collaborate with remote colleagues [15].

\section{B. Mixed reality and mobile devices}

The Augmented Reality (AR) form of mixed-reality is already present in many every-day applications, that are location or context aware, including the live-television broadcast of sports events [17] as it provides new ways of showing relationships and connections in the real world [18]. [19] shows the use of augmented reality in education and [20] reported examples of AR applications from specific domains such as architecture and tourism, that engage the user in an exploratory role (like in games) aimed at the discovery of additional material or content.

We shall consider the application of AR via (or to) mobile platforms including head-mounted devices, smartphones and tablets, focusing on the latter two as most smartphones and tablet (or mobile) devices contain three basic feedback-to-user channels which are sound speaker(s), a display screen and the ability to vibrate, which may be used for providing auditory, visual and haptic based AR respectively. Mobile devices also contain one or more of the following sensors: microphone, multi-touch input (display), camera, location (gps), accelerometer (for acceleration, rotation or orientation), ambient light level, which may be used to aid the augmentation process. For example, movements, gestures, physical orientation (roll, height, shaking) of the mobile device can be translated into powerful Human Computer Interface (HCI) interactions within a mixed-reality environment.

The low-computational power of mobile devices has implications for high-speed image processing (detection) required for tracking a marker, the process may be slower for partially visible markers. In AR, virtual objects are defined by shape-files that are rendered in 3D by a suitable graphics library or engine that also provide the ability to scale objects. In a technique used in mobile AR, the marker image is decomposed into unique set(s) of simple shapes and angles, which is then registered or encoded within the AR application as the marker. At run-time, high-speed marker recognition is based on real-time decomposition of images followed by partial grey-scale pattern matching against the registered set(s). The inclusion of angles allows the identification of the marker at different distances, resolutions and angles from the camera

Many of the existing examples of mixed-reality on mobile platforms focus on using $\mathrm{AR}$ in providing passive information (text, audio and video overlays) to users based on input from sensors about physical location, movement and gestures. However, other works such as [21] document the use of Augmented Virtuality (AV) on mobile devices for estimating power output of solar panels. While other works including [22] and [23] show the use of mobile AR in education.

\section{MiXED REALITY VISUALIZATION CUBICLE}

A mixed reality visualization cubicle may be created using a spatial arrangement of multiple markers. One or more AR markers are placed on each wall of the cubicle and each one provides a windowed view of the virtual environment. For example, a wall may have a single large (A3 or bigger) image or a set of smaller (A4) images.

Figure 3 shows the AR visualization cubicle jointly developed by Santa's Co (a software development company from Reggio Emilia, Italy), the Ulster University (UU) and the International Centre for Theoretical Physics (ICTP). The semi-immersive AR environment (cubicle) is composed of four large A3 markers, while three were positioned vertically, each on a separate wall (left, right and front from perspective of a user), the fourth was placed horizontal on the floor to provide a $180+90$ degree seamless exploratory view. That is, using this configuration, the cubicle may be used to provide a 180 degree view of the virtual world in 


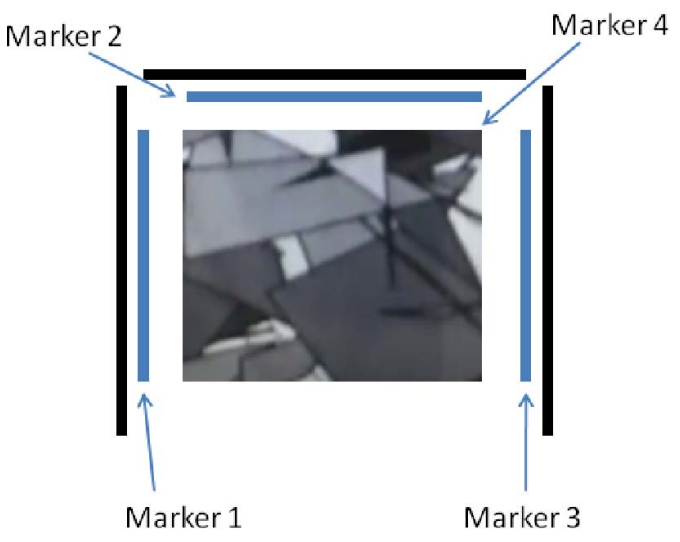

Figure 3. AR immersive cubicle.

the horizontal direction as well as a 90 degree angle in the vertical direction.

\section{A. Creating mobile Augmented Reality (mAR) applications}

Figure 4 shows the technical flow-chart for the sequence of steps implemented in a typical mixed reality (AR) application software. As shown, several distinct and complex software processing steps/stages are required in AR applications, these include managing hardware-sensors such as a hardware camera device (required for capturing a view of the real-world), image processing/detection (required for recognising markers), image rendering/texturizing (required for introducing virtual objects into the view of the real world) and a real-time event-driven programming model, which is required for managing user input and interactions between real-objects, virtual-objects and end-user [23].

The process of creating mixed-reality applications on mobile devices has benefited from the introduction of standard Application Programming Interfaces (API), frameworks and Software Development Kits (SDK) for various mobiledevice platforms. For example, developing software for smart-phones running the Android Operating System (Android) depend on the free Android SDK tools available for various software development environment [24]. Using frameworks such as the Android SDK simplify the software development process because they include standardized APIs for a wide range of hardware sensors including accelerometers, gyroscopes, proximity sensors, barometers, as well as, for handling input/output from touch-screen displays [25] and abstract hardware while also compensating for inconsistent behaviour by different devices (for example, poor resolution due to distance, motion blur and poor lighting/contrast situations) [26]. The Android SDK already contains some limited image processing functionality that is used exclusively for Face Detection, but this is not usable for $\mathrm{AR}$ as it lacks the ability to register arbitrary images/patterns for detection [23], however, there are several libraries or engines that provide 3D capabilities on Android platforms. [27] and [28] as well as other authors have used the "Unity3D" (game) engine for developing educational applications, while, other authors including [29] and [30] have combined the Vuforia AR library with other engines. Typically, in rendering, the real-time distance between a marker and camera lens, as well as, the relative angular orientation of the mobile device (obtained possible from accelerometer sensor) are important in computing the adequate scale and perspective of rendered objects.

Now-a-days, there are many commercial high-level SDKs for performing augmented reality on mobile platforms, although, some are free for non-commercial use. The Android applications presented here were developed by combining the Android SDK with a 3rd party image-processing SDK and another 3D rendering library/engine. In the future, it is possible that the free Android SDK would eventually include suitable image-processing and 3D rendering capabilities and maybe a dedicated framework/API for AR.

Obtaining data from sensors using the Android SDK is a relatively straight forward process as documented in [25] and it is sometimes possible to computationally derive functional data from sensors. For example, the common accelerometer sensor works by detecting the inertia of a suspended mass under the influence of acceleration and because the mass is subjected to gravitational force, its relative position during acceleration may be used to derive a tilt angle based on simple trigonometric operations.

Consider the 3-axis accelerometer device shown in Figure $5 \mathrm{a}$, which is composed of elastic elements and a suspended mass. When the device is not subject to acceleration and the suspended mass (or body) is at rest or at a zero-point. The readings or values from the 3 elastic elements at this zero point may be represented by $X 0, Y 0, Z 0$ respectively.

When the same accelerometer sensor is subject to an acceleration as shown in Figure 5b, the mass is displaced from its zero point and the readings from the elastic elements may be represented by $X 1, Y 1$ and $Z 1$ respectively.

A reasonably accurate single-axis tilt-angle of the mass with respect to the original position (Figure 5a) may be determined mathematically from the trigonometric (tangent) relationship of the other two axis (elastic elements) [31].

That is, calculating the tilt angle of the $X$ axis would be carried out as follows:

$$
\tan \theta_{x}=\frac{Z 1}{Y 1}
$$

or

$$
\theta_{x}=\arctan \left(\frac{Z 1}{Y 1}\right)
$$

In Equations (3) and (4), $\theta_{x}$ is in radians.

In practice, the readings from the accelerometer could be quite erratic and it is usual to stabilize the values using a filtering factor $k$ such that Equations (3) and (4) become 


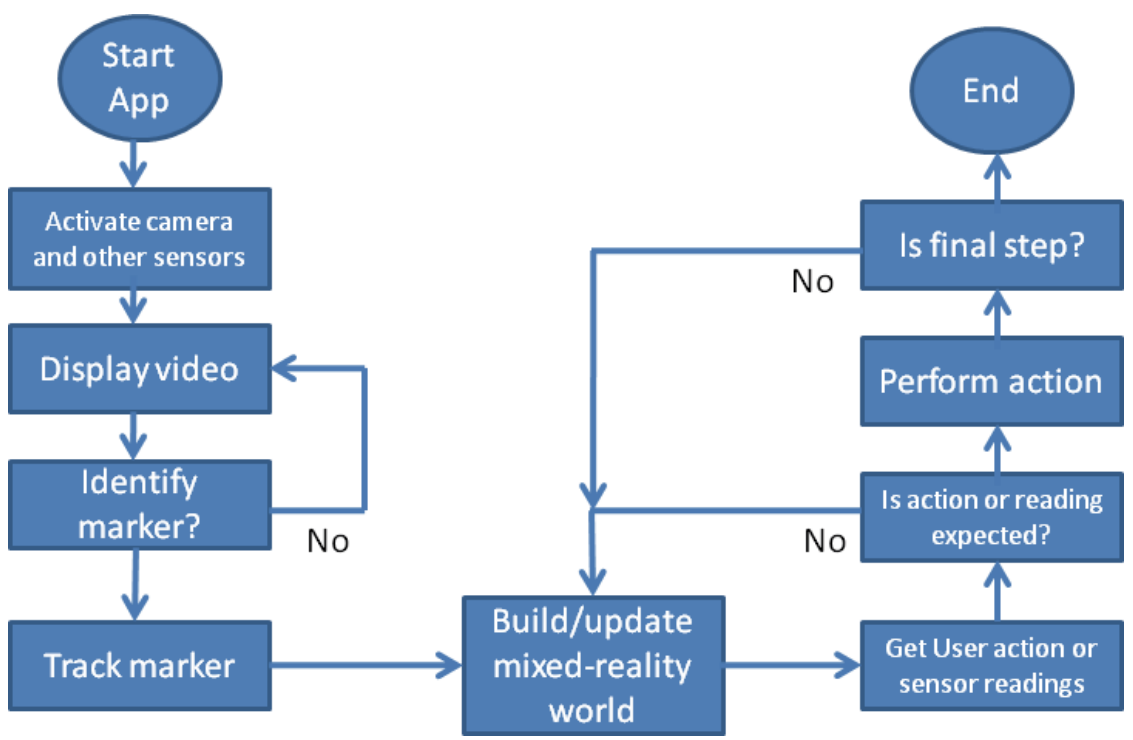

Figure 4. Technical flowchart for video see-through augmented reality on mobile devices [23]

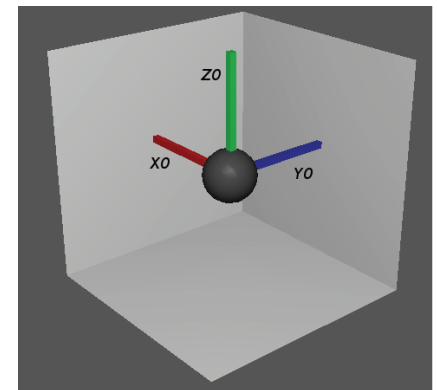

(a) No acceleration

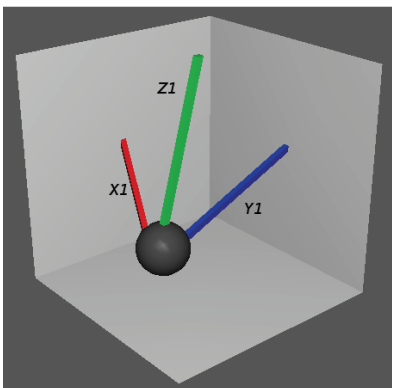

(b) Under acceleration

Figure 5. Accelerometer mass

$$
\tan \theta_{x}=\frac{Z 1(k)+Z 0(1-k)}{Y 1(k)+Y 0(1-k)}
$$

and

$$
\theta_{x}=\arctan \left(\frac{Z 1(k)+Z 0(1-k)}{Y 1(k)+Y 0(1-k)}\right)
$$

Practically the value of the filtering factor was determined as $0.98 f$ (where $f$ enforces IEEE single-precision float). Equation (6) may be implemented by the following pseudocode function, which would accept a 3-axis accelerometer reading and return the corresponding tilt angle values in degrees.

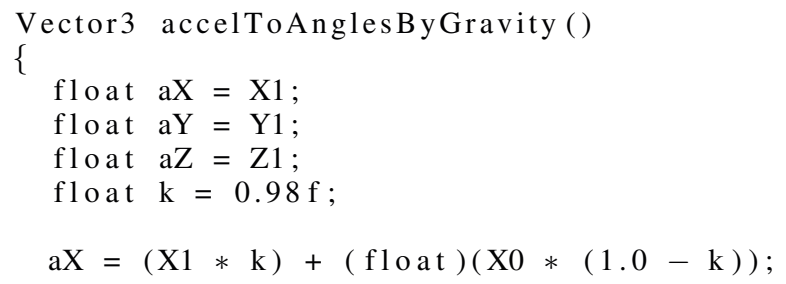

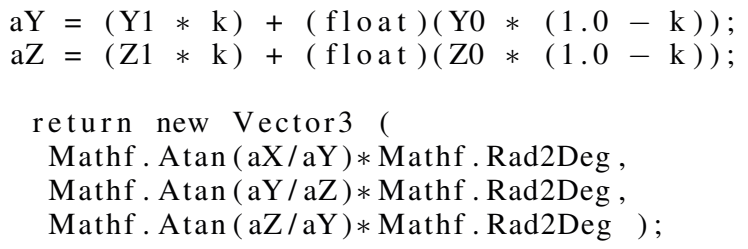

The development of a mixed-reality visualization cubicle involved the spartial placement of markers on each face of a cubicle as shown in Figure 3. Where each marker is part of a coordinated set and individually provides a windowed view of a virtual environment as shown in Figure 6.

\section{B. Limitation}

The cubicle provides a fully immersive experience if used with suitable AR goggles or head-mounted devices. Tablets and normal smart-phones alone provide a windowed semi-immersive view. The standard dimensions of a typical cubicle does not allow for group visualizations or use. 


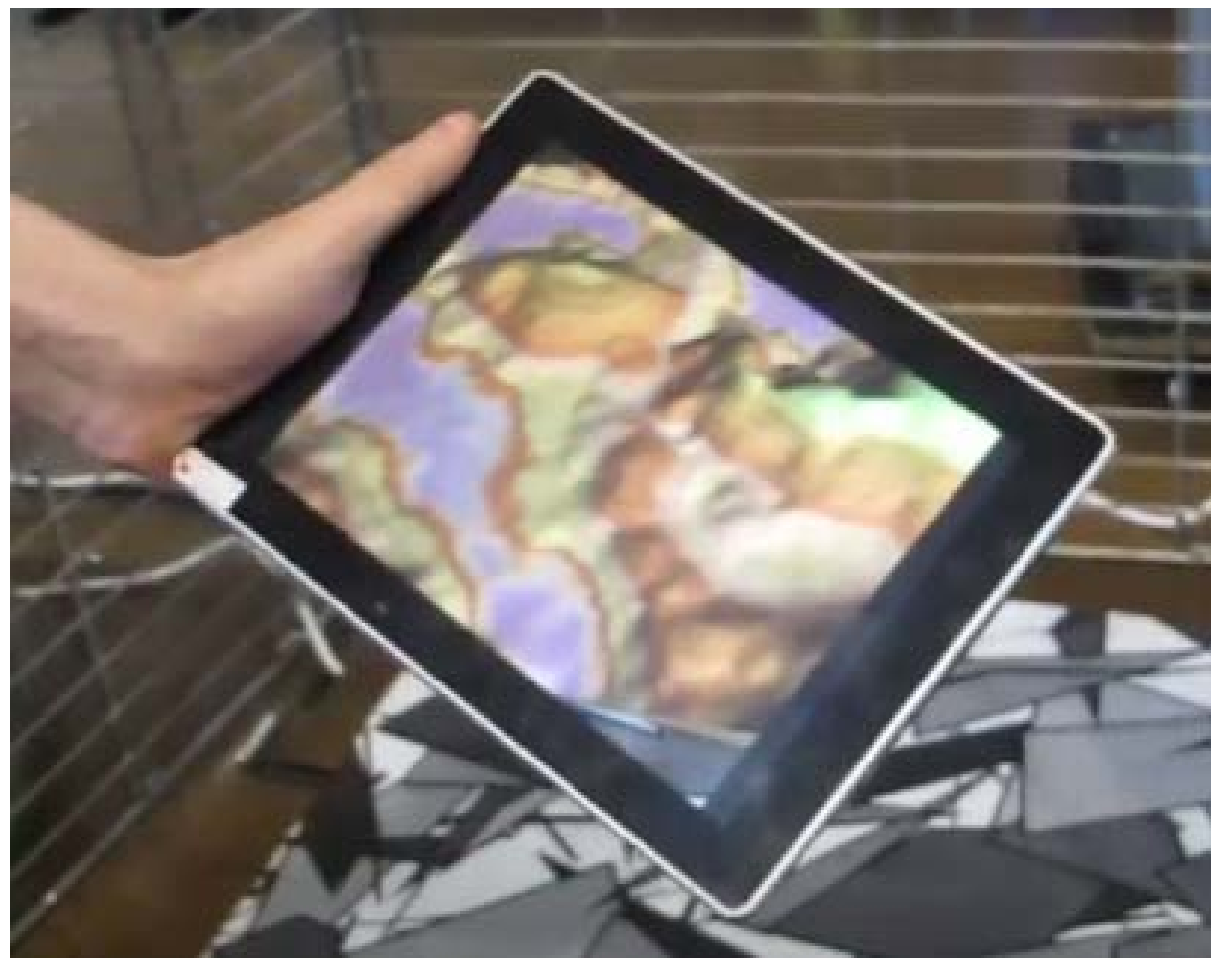

Figure 6. mobile device view inside immersive mixed-reality (AR) cubicle.

Table I

PROFILE OF RESPONDENTS

\begin{tabular}{|l|c|}
\hline Profile & Percentage(\%) \\
\hline Gender & 75.97 \\
Male & 19.48 \\
Female & 04.55 \\
Data not provided & \\
\hline Departments & 08.44 \\
Computational Science & 35.71 \\
Computer Science & 04.55 \\
Computer Engineering & 26.62 \\
Engineering & 03.90 \\
Mathematics & 16.23 \\
Physics & 04.55 \\
Data not provided & \\
\hline
\end{tabular}

Even if extra large cubicles are used, users usually work individually or in groups sometimes with individual view points of a common physical object or marker [32].

\section{Familiarity with $V R$ and $A R$}

Anonymous feedback was obtained from 150 academicians (students and researchers) from the Obafemi Awolowo University, Nigeria and the Addis Ababa University, Ethiopia alongside exposure to mobile AR technology. The consenting adult volunteers, who participated without incentives, risks and disadvantages in the international study were informed of the purpose, confidentiality of the study and the intended use of the collected data.
Table II

RESPONDENT'S FAMILIARITY WITH VR AND AR TECHNOLOGIES

\begin{tabular}{|l|c|c|}
\hline Response & VR (\%) & AR (\%) \\
\hline No & 34.43 & 35.32 \\
\hline Don't think so & 10.60 & 8.67 \\
\hline Don't know & 13.91 & 24.67 \\
\hline Maybe & 12.58 & 12.67 \\
\hline Yes & 28.48 & 18.67 \\
\hline
\end{tabular}

Table I shows resulting distribution of the study population across the selected disciplines of natural sciences and engineering. About $74 \%$ were undergraduate students and only $19 \%$ were female. As shown in Table II, participants were asked if they have used either Virtual Reality (VR) and Augmented Reality (AR) technologies.

The collected data show less than $30 \%$ had used VR environments compared with less than $20 \%$ who had used AR and suggest that VR systems are more readily available when compared with AR systems. Although, the mean age was between 21 - 24 years, about $70 \%$ of respondents were also first-time users of either VR and AR technologies.

The results obtained are consistent with the findings of [33] and [34] that educational use and research on augmented reality is still not common despite their continued classifications as emerging technologies [35] with enormous promise for educational use [34], [36]

It is possible that mixed reality cubicles as discussed in 
this paper would improve knowledge about both AR and VR technologies.

\section{CONCLUSION}

This paper has presented the implementation of a mixedreality visualization cubicle based on mobile Augmented Reality (AR) technology. The implementation uses spatially arranged AR markers to provide features typically available within Virtual Reality (VR) CAVEs. We discuss the costeffective creation of mixed reality applications for commodity mobile Information and Communication Technology (ICT) devices (smart-phone and tablet) as hardware are readily affordable/available to all and include a study of familiarity with VR and AR technologies in academic environments. Future work include the creation of an Experience Lab by the Artificial Intelligence and Applications Research Group at Ulster University, that involve the deployment of several enhanced mixed-reality visualization cubicles at Ulster University and the ICTP. Enhancements would involve using suitable head and chest-mounted mobile devices for visualizing and exploring fully-immersive AR environments and supporting joint visualizations and explorations by users in different geographically separate locations. Applications for the Experience Lab would include creating visualexperiential presence during videoconferencing meetings, immersive exploration of cities or tourism sites and the creation and use of "smart" AR markers based on Internet of Things (IoT) or similar sensors.

\section{ACKNOWLEDGMENT}

The authors would like to thank the School of Computing, Ulster University; the Telecommunications and ICT for Development (T/ICT4D) Laboratory, ICTP and Santa's Co, Regio-Emilia, Italy

\section{REFERENCES}

[1] C. Onime and O. Abiona, "3D mobile augmented reality interface for laboratory experiments," International Journal of Communications, Network and System Sciences, vol. 09, no. 04, pp. 67-76, 2016. [Online]. Available: http: //dx.doi.org/10.4236/ijens.2016.94006

[2] P. Milgram, H. Takemura, A. Utsumi, and F. Kishino, "Augmented reality: A class of displays on the reality-virtuality continuum," Telemanipulator and Telepresence Technologies, vol. SPIE 2351, pp. 282-292, 1994.

[3] J. Cecil, "The creation of virtual learning environments," in Innovations 2012: World Innovations in Enginnering Education and Research, W. Aung, V. Llic, O. Mertanen, J. Moscinski, and J. Uhomoibhi, Eds. Potomac: iNEER, 2012, pp. 263-273.

[4] P. Zahorik, "Assessing auditory distance perception using virtual acoustics," Journal of the Acoustical Society of America, vol. 111, pp. 1832-1846, 2002.
[5] H. Tan and A. Pentland, "Tactual displays for wearable computing," Personal Technologies, vol. 1, pp. 225-230, 1997.

[6] C. Basdogan, C.-H. Ho, M. A. Srinivasan, and M. Slater, "An experimental study on the role of touch in shared virtual environments," ACM Trans. Comput.-Hum. Interact., vol. 7, no. 4, pp. 443-460, Dec. 2000. [Online]. Available: http://doi.acm.org/10.1145/365058.365082

[7] J. Lanier, "Virtual reality: the promise of the future," Interactive Learning International, vol. 8, no. 4, pp. 275-279, 1992.

[8] J. Fox, B. Arena, and J. N. Bailenson, "Virtual reality: A survival guide for the social scientist," Journal of Media Psychology, vol. 21, no. 3, pp. 95-113, 2009.

[9] Santa'S Company, "Santaś co." Available from: http:// santascompany.blogspot.co.uk/, Reggio Emilia, Italy, May 2013, [Accessed 23 May 2013].

[10] R. Pausch, T. Crea, and M. Conway, "A literature survey for virtual environments: Military flight simulator visual systems and simulator sickness," Presence: Teleoper. Virtual Environ., vol. 1, no. 3, pp. 344-363, Jul. 1992. [Online]. Available: http://dl.acm.org/citation.cfm?id=195923.195962

[11] R. O'Toole, R. Playter, T. Krummel, W. Blank, N. Cornelius, W. Roberts, W. Bell, and M. Raibert, "Assessing skill and learning in surgeons and medical students using a force feedback surgical simulator," in Medical Image Computing and Computer-Assisted Interventation - MICCAI'98, ser. Lecture Notes in Computer Science, W. Wells, A. Colchester, and S. Delp, Eds. Springer Berlin Heidelberg, 1998, vol. 1496, pp. 899-909. [Online]. Available: http://dx.doi.org/10. 1007/BFb0056278

[12] J. Georgiou, K. Dimitropoulos, and A. Manitsaris, "A virtual reality laboratory for distance education in chemistry," vol. 1, no. 11, pp. 337 - 344, 2007. [Online]. Available: http://waset.org/Publications?p=11

[13] J. Cecil and J. Huber, "Virtual prototyping in engineering," in Virtual Engineering, J. Cecil, Ed. New Jersey: Momentum Press, 2010, pp. 1-15.

[14] Beckman Institute Illinois Simulator Laboratory: University of Illinois at Urbana.Champaign, "Beckman institute illinois simulator laboratory," Available from: http://isl.beckman. illinois.edu/Labs/CAVE/CAVE.html, September 2013, [Accessed 18 September 2013].

[15] M. Beaudouin-Lafon, S. Huot, M. Nancel, W. Mackay, E. Pietriga, R. Primet, J. Wagner, O. Chapuis, C. Pillias, J. Eagan, T. Gjerlufsen, and C. Klokmose, "Multisurface interaction in the wild room," Computer, vol. 45, no. 4, pp. 48-56, April 2012.

[16] C. Onime and O. Uhomoibhi, "Cost effective visualization of research data for cognitive development using mobile augmented reality," in Road Mapping Infrastructures for Advanced Visual Interfaces Supporting Big Data Applications in Virtual Research Environments (AVI 2016), 2016.

[17] R. Azuma, Y. Baillot, R. Behringer, S. Feiner, S. Julier, and B. MacInTyre, "Recent advances in augmented reality," IEEE Computer Graphics and Applications, vol. 21, no. 6, pp. 34 47, 2001. 
[18] J. O. Uhomoibhi, J. Palma, P. Alves, T. M. Restive, M. R. Piteira, O. S. F., and C. Fernandez, "Development of elearning in higher education and future directions," in Innovations 2011: World Innovations in Engineering Education and Research, W. Aung, V. Ilic, J. Moscinski, and J. Uhomoibhi, Eds. Potomac: iNEER, 2011, pp. 35-49.

[19] J. M. Andujar, A. Mejias, and M. A. Marquez, "Augmented reality for the improvement of remote laboratories: An augmented remote laboratory," Education, IEEE Transactions on, vol. 54, no. 3, pp. 492-500, 2011.

[20] E. FitzGerald, A. Adams, R. Ferguson, M. Gaved, Y. Mor, and R. Thomas, "Augmented reality and mobile learning: the state of the art," in 11th World Conference on Mobile and Contextual Learning (mLearn 2012), M. Specht, M. Sharples, and J. Multisilta, Eds. Helsinki: CEUR, 2012, pp. 62-69.

[21] C. Onime, J. Uhomoibhi, and E. Pietrosemoli, "An augmented virtuality based solar energy power calculator in electrical engineering," International Journal of Engineering Pedagogy, vol. 5, no. 1, pp. 4-7, Jan 2015.

[22] C. Onime, J. Uhomoibhi, and M. Zennaro, "A low cost implementation of an existing hands-on laboratory experiment in electronic engineering," International Journal of Engineering Pedagogy, vol. 4, no. 4, pp. 1-3, Oct 2014.

[23] C. Onime, J. Uhomoibhi, and S. Radicella, "Mare: Mobile augmented reality based experiments in science, technology and engineering," in Online Experimentation: Emerging Technologies and IoT, M. T. R. Restivo, A. Cardoso, and A. M. Lopez, Eds. Barcelona, Spain: IFSA Publishing, Dec. 2015.

[24] S. Fiawoo and R. Sowah, "Design and development of an android application to process and display summarised corporate data," in Adaptive Science Technology (ICAST), 2012 IEEE 4th International Conference on, Oct 2012, pp. 86-91.

[25] Android Developers, "Introduction to android," Available from: http://developer.android.com/guide/index.html, November 2014 .

[26] A. Mutholib, T. Gunawan, and M. Kartiwi, "Design and implementation of automatic number plate recognition on android platform," in Computer and Communication Engineering (ICCCE), 2012 International Conference on, July 2012, pp. 540-543.

[27] S. L. Kim, H. J. Suk, J. H. Kang, J. M. Jung, T. Laine, and J. Westlin, "Using unity $3 \mathrm{~d}$ to facilitate mobile augmented reality game development," in Internet of Things (WF-IoT), 2014 IEEE World Forum on, March 2014, pp. 21-26.

[28] S. Wang, Z. Mao, C. Zeng, H. Gong, S. Li, and B. Chen, "A new method of virtual reality based on unity3d," in Geoinformatics, 2010 18th International Conference on, June 2010, pp. 1-5.

[29] B. Sobota, S. Korecko, and F. Hrozek, "Mobile mixed reality," in Emerging eLearning Technologies and Applications (ICETA), 2013 IEEE 11th International Conference on, Oct 2013, pp. 355-358.
[30] C. Xiao and Z. Lifeng, "Implementation of mobile augmented reality based on vuforia and rawajali," in Software Engineering and Service Science (ICSESS), 2014 5th IEEE International Conference on, June 2014, pp. 912-915.

[31] C.-L. Hsu, W.-C. Chou, and W.-Y. Lin, "A digital tilt converter for three-axis accelerometers," in Consumer Electronics (ISCE), 2013 IEEE 17th International Symposium on, June 2013, pp. 19-20.

[32] M. Billinghurst, H. Kato, and I. Poupyrev, "The magicbook - moving seamlessly between reality and virtuality," IEEE Computer Graphics and Applications, vol. 21, no. 3, pp. 6-8, 2001 .

[33] S. Martin, G. Diaz, E. Sancristobal, R. Gil, M. Castro, and J. Peire, "New technology trends in education Seven years of forecasts and convergence," Computers \& Education, vol. 57, no. 3, pp. 1893-1906, 2011. [Online]. Available: http://www. sciencedirect.com/science/article/pii/S0360131511000844

[34] D. Nincarean, M. B. Alia, N. D. A. Halim, and M. H. A. Rahman, "Mobile augmented reality: The potential for education," Procedia - Social and Behavioral Sciences, vol. 103, no. 0, pp. 657 - 664, 2013, 13th International Educational Technology Conference. [Online]. Available: http://www.sciencedirect.com/science/ article/pii/S1877042813038305

[35] L. Wenguang, "Study on characteristic of emerging technology," in Management and Service Science (MASS), 2011 International Conference on, Aug 2011, pp. 1-5.

[36] New Media Consortium, "Horizon report 2014 k-12 edition," Available from: http://cdn.nmc.org/media/ 2014-nmc-horizon-report-k12-En.pdf, 2014, [Accessed 7 July 2014]. 